\title{
Impact of broad categorization on statistical results: How underrepresented minority designation can mask the struggles of both Asian American and African American students
}

\author{
Devyn Shafer®, ${ }^{*}$ Maggie S. Mahmood®, and Tim Stelzer® \\ University of Illinois at Urbana-Champaign, Department of Physics, \\ 1110 West Green Street, Urbana, Illinois 61801, USA
}

(Received 25 September 2020; accepted 15 February 2021; published 4 March 2021)

\begin{abstract}
Although recent research has reported equity gains in the university-level physics classroom, there remains evidence of significant inequities by race. We conducted a series of multiple linear regressions to examine the magnitude of these inequities in introductory mechanics final exam scores. When we followed a common method of grouping students by underrepresented minority (URM) status in our statistical analysis, we found that when controlling for prior knowledge, based on ACT math and physics placement test scores, there was no evidence of racial inequities. However, when we performed the same analysis but replaced URM status with separate groups for each race or ethnicity reported to the university, we found that African American and Asian American students, and to a lesser extent, Hispanic students, underperformed in their physics course relative to their non-Hispanic White American peers, even when controlling for prior knowledge. We conclude that grouping students by URM status may not be sufficient to detect patterns of academic difficulties experienced by specific racial and ethnic groups of students. Furthermore, these results lead us to believe that there is still work to be done at the university level to provide a learning environment supportive of students of all backgrounds.
\end{abstract}

DOI: 10.1103/PhysRevPhysEducRes.17.010113

\section{INTRODUCTION}

In the United States, race, income, and educational resource availability are tightly intertwined [1]. Systemic oppression of African American, Asian American, Hispanic, and Native American people has persisted since before the nation's founding. Consequently, education researchers study the impact of these dynamic structures of oppression on the educational and career attainment of people in historically oppressed minority groups in order to assess institutional priorities and recommend interventions designed to repay the educational debts owed to these groups [2-7].

In 2019, Salehi et al. [8] published a study of college student performance on introductory mechanics final exams and found that when controlling for SAT or ACT math scores and Force Concept Inventory (FCI) [9] or Force and Motion Conceptual Evaluation (FMCE) [10] scores from the beginning of the semester, the regression coefficient for underrepresented minority (URM) status became small and no longer statistically significant. The authors concluded that student incoming preparation is a

\footnotetext{
*deshafe2@illinois.edu
}

Published by the American Physical Society under the terms of the Creative Commons Attribution 4.0 International license. Further distribution of this work must maintain attribution to the author(s) and the published article's title, journal citation, and DOI. major contributor to demographic performance gaps. In this paper, we replicate the results of Salehi et al. and extend the investigation by considering alternative student groupings in the statistical analysis.

\section{METHODS}

We examined student performance in a calculus-based physics 1 course at a large midwestern university. All physics and engineering students at the university are required to take this course or demonstrate proficiency in its content. It is the first required physics course in a three-semester sequence. Most students take the course in the spring of their freshman year.

We used data from the 8553 students who took the course in the spring semester from 2012 through 2019. The spring semester was chosen because it is the recommended semester for students to take the course (with an average of 1069 students per semester compared to an average of 727 per semester in the fall between 2011 and 2019). The data from the spring are more homogeneous, perhaps in part because students taking the course in the fall are either ahead or behind with respect to the typical course pathway for engineering students. $96 \%$ of the students taking the course in the spring were freshman and 3\% were sophomores. In contrast, $81 \%$ of the fall students were freshmen and $17 \%$ were sophomores. Although we focus on the spring data in this paper, we included a parallel analysis for the fall data in Appendix A. 
The data include students' race and ethnicity, gender, ACT and SAT math scores, physics placement test scores, and course exam scores. Correlations among the continuous variables used in our analysis are shown in Appendix B. Because $96 \%$ of the students had ACT scores on record with the university, we converted the remaining $4 \%$ of SAT-only scores to an equivalent ACT score for our analysis using the conversion chart published by ACT [11]. We have not administered concept inventories such as the FCI and the FMCE to our students as was done by Salehi et al. [8], so we included our physics placement test in the analysis instead. This test is different in content from concept inventories, but like the concept inventories, it provides more information on student physics preparation than the ACT or SAT alone. The physics placement test is completed online by students the summer before their freshman year to determine whether they should take physics 1 right away or begin with a preparatory course. The test consists of 13 multiple choice questions of physics and mathematics content and is reproduced in Appendix C. A summary of student enrollment and test scores can be found in Table I. These values are fairly consistent from year to year.

We used demographic information reported by the students to the Office of the Registrar. A summary of the data as used for the analysis is in Table II. Nearly half $(45 \%)$ of the students reported that they were White only. About a quarter (23\%) identified as Asian American, 17\% were international students, $9 \%$ were Hispanic, and just 2\% were African American. Fewer than $1 \%$ of the students identified as American Indian/Alaskan Native (AIAN) or Native Hawaiian/Pacific Islander (NHPI).

Demographics are difficult to summarize and report because of the intersectionality of many of the students. Students who reported belonging in multiple groups were categorized according to the order of priority used by the university registration system: international, Hispanic, multirace. For example, an international student who identified as White and Hispanic would be categorized as international. Table III shows the numbers of students who reported belonging in multiple groups. It is notable how few students are grouped in the AIAN and NHPI categories in Table II. Table III shows that most of the students in these groups also belong to other groups,

TABLE I. Means and standard deviations (SD) of enrollment numbers and student test scores.

\begin{tabular}{lrr}
\hline \hline Characteristic & Mean & SD \\
\hline Students per term & 1069 & 47 \\
Math ACT score (out of 36) & 32 & 3 \\
Placement test score & $74 \%$ & $20 \%$ \\
First exam score & $80 \%$ & $15 \%$ \\
Second exam score & $77 \%$ & $15 \%$ \\
Third exam score & $76 \%$ & $16 \%$ \\
Final exam score & $75 \%$ & $16 \%$ \\
\hline \hline
\end{tabular}

TABLE II. Student demographics.

\begin{tabular}{lcc}
\hline \hline Group & Number & Percentage \\
\hline AIAN $^{\mathrm{a}}$ & 5 & $<1$ \\
Asian American & 1948 & 23 \\
African American & 192 & 2 \\
Hispanic & 752 & 9 \\
International & 1489 & 17 \\
Multirace & 310 & 4 \\
NHPI $^{\mathrm{b}}$ & 5 & $<1$ \\
Non-Hispanic White American & 3852 & 45 \\
Total & 8553 & 100 \\
\hline \hline
\end{tabular}

${ }^{\mathrm{a}}$ American Indian/Alaskan Native.

${ }^{\mathrm{b}}$ Native Hawaiian/Pacific Islander.

particularly White and Hispanic for AIAN students and Asian and White for NHPI students. Because of the very small number of students belonging to these two categories alone, we elect not to report statistical results for these groups to protect their privacy, although we did include them in the models for completeness. Another notable characteristic of the demographic data is that the vast majority of international students (92\%) are Asian. These international Asian students have been separated from the Asian American students in our analysis because we believe their experiences may be substantially different. Although students self-reported their racial and ethnic groups, we recognize that the specific experiences of students within each of the groups discussed in this paper still vary widely. The cultural and social heterogeneity of students in these defined racial and ethnic groups makes it challenging to draw any concrete conclusions about the specific effects of the student experience on our physics exam performance outcome findings.

We conducted a series of multiple linear regression analyses [12] to examine how ACT math scores, physics placement test scores, race, and ethnicity can predict final exam scores in physics 1 . In particular, we compared models using the groupings presented in Table II with models using the binary underrepresented minority categorization. For these models, we followed the methodology of Salehi et al. [8], categorizing White and Asian students who do not also identify as Black, Hispanic, AIAN, or NHPI as non-URMs and students reporting Black, Hispanic, AIAN, or NHPI identities as URMs. Using these criteria, 1156 students were classified as URMs, and 7397 were classified as non-URMs. In both sets of models, we looked at whether controlling for ACT math scores and physics placement test scores, a rough proxy for preparation, could eliminate the effect of race in predicting final exam scores. We normalized the continuous variables (ACT, physics placement test, and course exam scores) so that results could be interpreted as the number of standard deviations of difference predicted in final exam score for a 1 standard deviation increase in a continuous predictor variable, allowing for a direct comparison of 
TABLE III. Student intersectionality. Numbers on the diagonal represent students who reported only one category. Values do not add up to the total number of students because some students reported belonging to more than two groups.

\begin{tabular}{|c|c|c|c|c|c|c|c|}
\hline Group & $\mathrm{AIAN}^{\mathrm{a}}$ & Asian & Black & $\mathrm{NHPI}^{\mathrm{b}}$ & White & Hispanic & International \\
\hline AIAN & 5 & & & & & & \\
\hline Asian & 7 & 1911 & & & & & \\
\hline Black & 9 & 19 & 188 & & & & \\
\hline NHPI & 2 & 23 & 1 & 5 & & & \\
\hline White & 45 & 218 & 47 & 15 & 3811 & & \\
\hline Hispanic & 32 & 44 & 9 & 4 & 515 & 199 & \\
\hline International & 2 & 1365 & 14 & 0 & 93 & 32 & 6 \\
\hline
\end{tabular}

${ }^{\mathrm{a}}$ American Indian/Alaskan Native.

${ }^{\mathrm{b}}$ Native Hawaiian/Pacific Islander.

coefficients. For categorical variables, we dummy coded the URM model so that URMs were coded with ones and nonURMs with zeroes. Similarly, in the differentiated models, students in each non-White category were coded with ones so that the model for non-Hispanic White American students was given by setting each of these terms to 0 . Thus, in the model controlling for prior test scores, the coefficient for each demographic group represents the difference in standardized final exam scores between that group and nonHispanic White American students with the same ACT math and physics placement test scores.

In checking the assumptions of linear regression for our models, we encountered a violation of homogeneity of variances for the differentiated models using the spring data and for all models using the fall data. This violation was identified using the studentized Breusch-Pagan test [13]. Heterogeneity of variances may affect the validity of error bars but not the coefficients, so we applied a correction to obtain more robust error bars and $p$ values [14]. Because of the violation of this assumption, the $F$ test was not appropriate, so we conducted the Wald test [15] instead. We have reported $F$-test results where the assumptions of linear regression were met and Wald test $\chi^{2}$ values for all models to allow for comparison.
We considered implementing multilevel mixed effects models with a random intercept for year [16]. However, we found that the intraclass correlation coefficient (ICC) for year was 0.009 , well below the recommended cutoff of 0.05 for including a random effect term $[17,18]$. Furthermore, the Akaike information criterion (AIC) [12] for our model that included separate racial and ethnic categories, ACT math scores, and physics placement test scores was slightly lower $(\Delta \mathrm{AIC}=0.38)$ without the random effect term of year than with it. Both of these pieces of information indicate that multilevel modeling would be an unnecessary complication for analyzing the data used in this study.

\section{RESULTS}

\section{A. Binary model}

We grouped the students and conducted our analysis according to the methodology of Salehi et al. [8] to construct the binary URM model of Table IV [19]. With URM status as the only predictor for final exam score, we found a $\beta$ value of -0.353 , indicating that URMs earned scores about one-third of a standard deviation lower on the final exam on average than non-URMs, where a URM is defined as someone who identifies as Black, NHPI, AIAN,

TABLE IV. Binary models predicting physics 1 final exam scores.

\begin{tabular}{|c|c|c|c|c|c|c|c|c|c|}
\hline \multirow[b]{2}{*}{ Predictor } & \multicolumn{3}{|c|}{ Model 1} & \multicolumn{3}{|c|}{ Model 2} & \multicolumn{3}{|c|}{ Model 3} \\
\hline & $\beta$ & SE & $p$ & $\beta$ & SE & $p$ & $\beta$ & SE & $p$ \\
\hline $\begin{array}{l}\text { URM } \\
\text { ACT Math } \\
\text { Placement Test }\end{array}$ & -0.353 & 0.031 & $<0.001$ & $\begin{array}{c}-0.083 \\
0.324\end{array}$ & $\begin{array}{l}0.031 \\
0.011\end{array}$ & $\begin{array}{c}0.007 \\
<0.001\end{array}$ & $\begin{array}{l}-0.055 \\
0.222 \\
0.237\end{array}$ & $\begin{array}{l}0.030 \\
0.011 \\
0.011\end{array}$ & $\begin{array}{l}0.069 \\
<0.001 \\
<0.001\end{array}$ \\
\hline $\begin{array}{l}F \\
d f \\
a d j . R^{2} \\
p\end{array}$ & & $\begin{array}{c}126.5 \\
1,8551 \\
0.014 \\
<0.001\end{array}$ & & & $\begin{array}{c}534.7 \\
2,8550 \\
0.111 \\
<0.001\end{array}$ & & & $\begin{array}{c}527.2 \\
3,8549 \\
0.156 \\
<0.001\end{array}$ & \\
\hline $\begin{array}{l}\chi^{2} \\
d f \\
p\end{array}$ & & $\begin{array}{c}126.5 \\
1 \\
<0.001\end{array}$ & & & $\begin{array}{c}1069.5 \\
2 \\
<0.001\end{array}$ & & & $\begin{array}{c}1581.6 \\
3 \\
<0.001\end{array}$ & \\
\hline
\end{tabular}




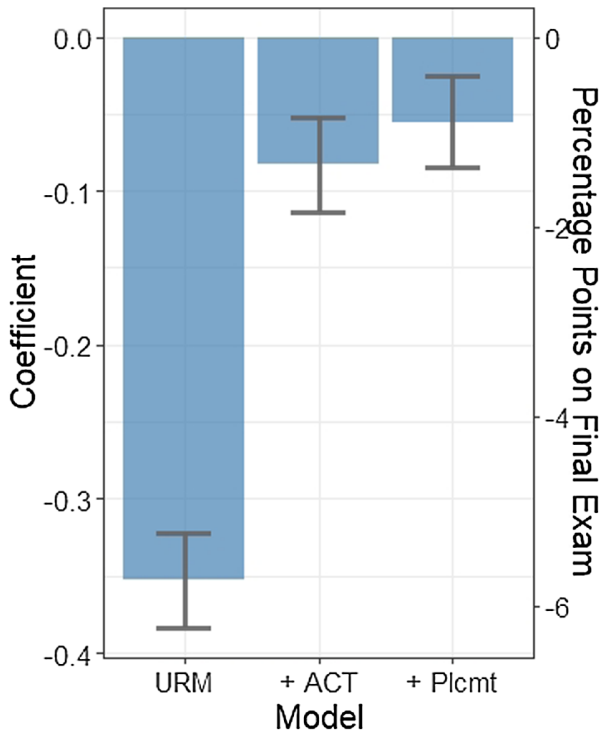

FIG. 1. Multiple linear regression coefficients of the URM variable in the binary models reported in Table IV. Coefficients represent the standardized difference in final exam performance between non-URMs (Asian and White students) and URMs (Black, Hispanic, AIAN, and NHPI students). The error bars represent the standard error for each coefficient. The URM coefficient had $p<0.01$ for models 1 and 2 (URM alone and $\mathrm{URM}+$ ACT Math, respectively), but $p=0.069$ for model 3, in which the placement test was included.

or Hispanic. Adding ACT math scores to the model reduced the URM coefficient to -0.083 , indicating that when compared with non-URMs with the same ACT math score, URMs scored 0.083 standard deviations lower on the final exam. Meanwhile, the ACT math score was a strong predictor of final exam performance across student groups, with students scoring about one-third of a standard deviation higher $(\beta=0.324)$ on the final exam for every standard deviation increase in ACT math score. Finally, adding the placement test further reduced the URM coefficient to -0.055 and rendered it statistically nonsignificant. However, ACT math score and placement test score both had large, positive coefficients: 0.222 and 0.237 , respectively. The URM coefficients for each of these three models are represented visually in Fig. 1. These results suggest that student performance differences by URM status may be accounted for by the disparity in their preparation for the introductory mechanics course, a finding consistent with Salehi et al. [8].

\section{B. Differentiated model}

Next, we considered the more differentiated model shown in Table V, in which African American, Asian American, Hispanic, International, Multirace, AIAN, NHPI, and non-Hispanic White American were all considered as separate groups. The $\beta$ values were large and negative for the African American, Asian American, and Hispanic groups in model 4, which included only racial and ethnic groups as predictors. African American students scored almost two-thirds of a standard deviation lower on the final exam than non-Hispanic White American students on average, as indicated by the $\beta$ value of -0.650 . Asian American students scored about a fifth of a standard deviation lower than non-Hispanic White American students on the final exam $(\beta=-0.216)$, and Hispanic students about one-third of a standard deviation lower $(\beta=-0.329)$. Even with the more conservative adjustment we made to account for the heterogeneity of variances, the standard errors were small for the African American, Asian American, and Hispanic variables (0.084, 0.027, and 0.039, respectively), and the $p$ values were less than 0.001 .

We added ACT math scores in model 5 . The coefficients for African American and Hispanic students reduced in magnitude to -0.344 and -0.0130 , respectively. However, the coefficient for Asian American students increased in magnitude to -0.321 . Meanwhile, the coefficient for ACT math

TABLE V. Differentiated models predicting physics 1 final exam scores ${ }^{\mathrm{a}}$.

\begin{tabular}{|c|c|c|c|c|c|c|c|c|c|}
\hline \multirow[b]{2}{*}{ Predictor } & \multicolumn{3}{|c|}{ Model 4} & \multicolumn{3}{|c|}{ Model 5} & \multicolumn{3}{|c|}{ Model 6} \\
\hline & $\beta$ & SE & $p$ & $\beta$ & SE & $p$ & $\beta$ & SE & $p$ \\
\hline African American & -0.650 & 0.084 & $<0.001$ & -0.344 & 0.083 & $<0.001$ & -0.300 & 0.080 & $<0.001$ \\
\hline Asian American & -0.216 & 0.027 & $<0.001$ & -0.321 & 0.026 & $<0.001$ & -0.353 & 0.025 & $<0.001$ \\
\hline Hispanic & -0.329 & 0.039 & $<0.001$ & -0.130 & 0.037 & $<0.001$ & -0.134 & 0.036 & $<0.001$ \\
\hline International & 0.312 & 0.031 & $<0.001$ & 0.037 & 0.031 & 0.231 & -0.100 & 0.031 & 0.001 \\
\hline Multirace & -0.045 & 0.062 & 0.473 & -0.040 & 0.059 & 0.496 & -0.086 & 0.059 & 0.142 \\
\hline ACT math & & & & 0.323 & 0.011 & $<0.001$ & 0.236 & 0.012 & $<0.001$ \\
\hline Placement test & & & & & & & 0.241 & 0.011 & $<0.001$ \\
\hline$\chi^{2}$ & & 355.3 & & & 1247.6 & & & 1912.5 & \\
\hline$d f$ & & 7 & & & 8 & & & 9 & \\
\hline$p$ & & $<0.001$ & & & $<0.001$ & & & $<0.001$ & \\
\hline
\end{tabular}

${ }^{a}$ AIAN and NHPI students were included in the model, but the coefficients for these groups are not reported here to protect the privacy of the students, since these groups are very small. 


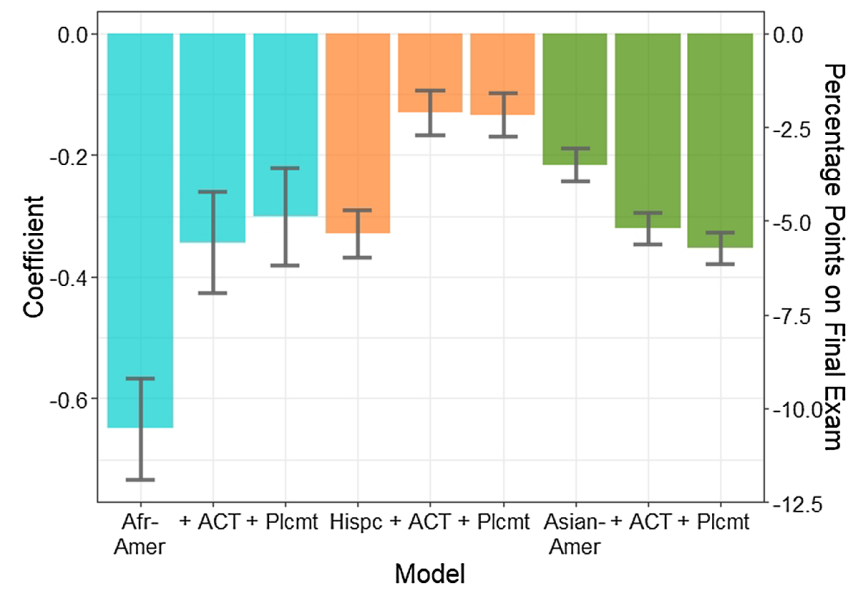

FIG. 2. Multiple linear regression coefficients from the differentiated models reported in Table V. Coefficients represent the standardized difference in final exam performance between nonHispanic White American students and the specified group. The error bars represent the standard error for each coefficient. The coefficients had $p<0.001$ for all three models.

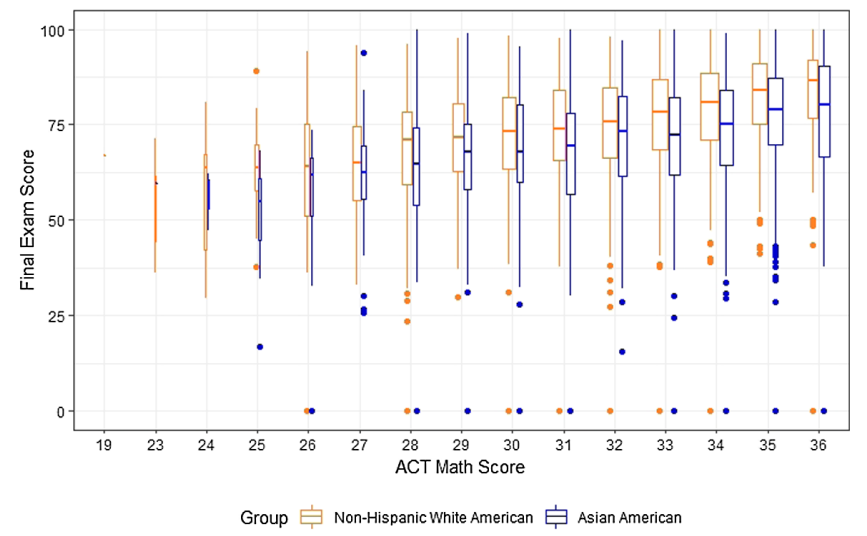

FIG. 3. Asian American and non-Hispanic White American student performance on the final exam by ACT math score.

score was very similar to what was found with the binary model, with students once again scoring about one third of a standard deviation higher $(\beta=0.323)$ on the final exam for every increase of one standard deviation in ACT math score.
Finally, we added the physics placement test in model 6. The coefficients for both the African American and Asian American groups remained large and negative: $-0.300 \pm$ 0.080 and $-0.353 \pm 0.025$, respectively, with $p$ values less than 0.001. The coefficient for the Hispanic group was smaller than these, but still negative at $-0.134 \pm 0.036$ with $p<0.001$. ACT math score and physics placement test score were both important predictors, with coefficients of $0.236 \pm 0.012$ and $0.241 \pm 0.011$, respectively, and $p<0.001$. These coefficients are represented visually in Fig. 2.

We examined student performance on the final exam by ACT score and group. A set of box plots comparing the performance of Asian American students with that of non-Hispanic White American students on the final exam by ACT math score is shown in Fig. 3. In this series of box plots [20], the middle bar corresponds to the median exam score, the top of each box corresponds to the 75th percentile, and the bottom of each box corresponds to the 25 th percentile. The whiskers extending from the edges of the boxes are of a length capped at one-and-a-half times the interquartile range, the difference between the 75th and 25 th percentile scores. Scores outside these parameters are considered outliers and represented as points on the plot. We observe that across all ACT math scores, non-Hispanic White American students consistently earn higher final exam scores than Asian American students with the same ACT math score, and the difference between median scores is fairly constant.

One distinct feature of the Asian American group is that, on average, they performed better on the ACT math test and the physics placement test than non-Hispanic White American students but scored lower on all course exams. This is in contrast to the performance of the African American and Hispanic students, who scored lower than non-Hispanic White American students on all measures. The raw scores for each group are shown in Table VI.

\section{Using course exams to predict final exam}

Finally, we considered whether the effect of race could be eliminated in the model by controlling for performance on exams taken throughout the course. These models are shown

TABLE VI. Mean test scores by group. ACT Math scores are reported as raw scores, whereas the remaining exam scores are reported as percentages. Standard deviations are included in parentheses.

\begin{tabular}{lcccccc}
\hline \hline Group & ACT math & Placement test $(\%)$ & Exam 1 (\%) & Exam 2 (\%) & Exam 3 (\%) & Final exam (\%) \\
\hline African American & $29(3)$ & $60(20)$ & $72(17)$ & $68(17)$ & $67(17)$ & $65(19)$ \\
Asian American & $33(3)$ & $75(19)$ & $77(16)$ & $75(15)$ & $75(16)$ & $72(16)$ \\
Hispanic & $30(3)$ & $66(20)$ & $75(17)$ & $73(15)$ & $73(16)$ & $70(16)$ \\
International & $34(2)$ & $88(14)$ & $85(15)$ & $82(15)$ & $82(17)$ & $80(17)$ \\
Multirace & $32(3)$ & $74(19)$ & $79(17)$ & $76(15)$ & $76(17)$ & $74(17)$ \\
Non-Hispanic White American & $32(3)$ & $70(19)$ & $80(15)$ & $77(14)$ & $76(15)$ & $75(14)$ \\
URM & $30(3)$ & $66(20)$ & $75(17)$ & $72(15)$ & $72(17)$ & $70(17)$ \\
Non-URM & $33(3)$ & $75(19)$ & $80(15)$ & $77(15)$ & $77(16)$ & $75(16)$ \\
\hline \hline
\end{tabular}


TABLE VII. Models with course exam scores predicting physics 1 final exam scores.

\begin{tabular}{|c|c|c|c|c|c|c|c|c|c|}
\hline \multirow[b]{2}{*}{ Predictor } & \multicolumn{3}{|c|}{ Model 7} & \multicolumn{3}{|c|}{ Model 8} & \multicolumn{3}{|c|}{ Model 9} \\
\hline & $\beta$ & SE & $p$ & $\beta$ & SE & $p$ & $\beta$ & SE & $p$ \\
\hline African American & -0.237 & 0.072 & $<0.001$ & -0.161 & 0.064 & 0.012 & -0.117 & 0.058 & 0.045 \\
\hline Asian American & -0.178 & 0.022 & $<0.001$ & -0.124 & 0.019 & $<0.001$ & -0.114 & 0.017 & $<0.001$ \\
\hline Hispanic & -0.083 & 0.030 & 0.006 & -0.079 & 0.028 & 0.005 & -0.084 & 0.025 & $<0.001$ \\
\hline International & -0.058 & 0.025 & 0.020 & -0.040 & 0.022 & 0.061 & -0.056 & 0.019 & 0.004 \\
\hline Multirace & -0.034 & 0.047 & 0.475 & -0.023 & 0.044 & 0.595 & -0.025 & 0.037 & 0.504 \\
\hline ACT math & 0.067 & 0.011 & $<0.001$ & 0.016 & 0.010 & 0.099 & 0.014 & 0.009 & 0.095 \\
\hline Placement test & 0.140 & 0.010 & $<0.001$ & 0.068 & 0.009 & $<0.001$ & 0.046 & 0.008 & $<0.001$ \\
\hline Exam 1 & 0.564 & 0.011 & $<0.001$ & 0.326 & 0.012 & $<0.001$ & 0.208 & 0.011 & $<0.001$ \\
\hline Exam 2 & & & & 0.457 & 0.013 & $<0.001$ & 0.265 & 0.012 & $<0.001$ \\
\hline Exam 3 & & & & & & & 0.418 & 0.017 & $<0.001$ \\
\hline$\chi^{2}$ & & 5529.0 & & & 8296.2 & & & 11366.8 & \\
\hline$d f$ & & 10 & & & 11 & & & 12 & \\
\hline$p$ & & $<0.001$ & & & $<0.001$ & & & $<0.001$ & \\
\hline
\end{tabular}

in Table VII. We checked for multicollinearity and concluded that it was not a concern, as indicated by variance inflation factor (VIF) values less than 3. The coefficients for African American, Asian American, ACT math, and physics placement test decreased in magnitude for each exam added to the model. Meanwhile, as expected, the exam scores were highly predictive of student performance on the final exam, with a predicted increase of $0.564 \pm 0.011$ standard deviations on the final exam (nine percentage points) for every increase of 1 standard deviation (15 percentage points) on the first exam in model 7 , which added only exam 1 to model 6 . In model 9, exams 1,2 , and 3 had $\beta$ values of $0.208 \pm$ $0.011,0.265 \pm 0.012$, and $0.418 \pm 0.017$. However, the

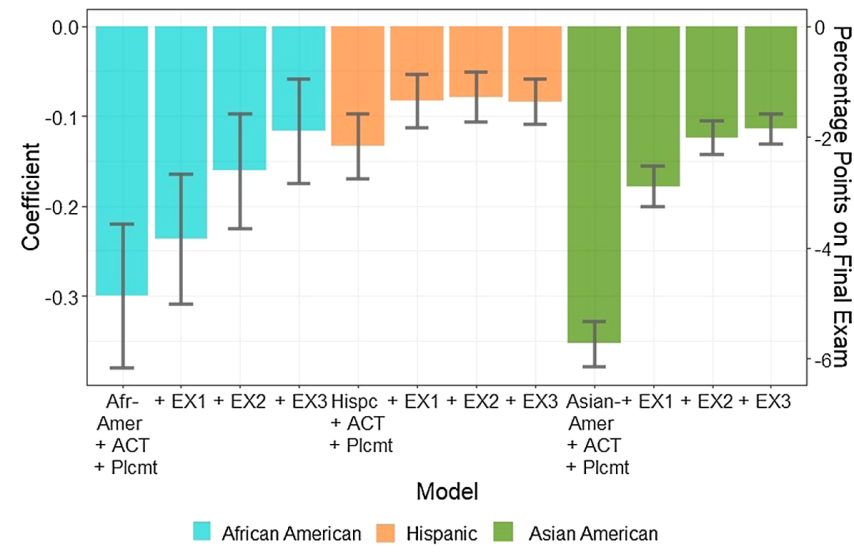

FIG. 4. Multiple linear regression coefficients from the exam models reported in Table VII with the coefficient from model 6 of Table V included for comparison. Model 6 is represented by the leftmost bar for each racial or ethnic group, and models 7-9 follow consecutively. Coefficients represent the standardized difference in final exam performance between non-Hispanic White American students and the specified group. The error bars represent the standard error for each coefficient. All coefficients are statistically significant with $p<0.05$. predictive power of race and ethnicity persisted, even controlling for exam performance throughout the course. Exam 3 typically takes place only two weeks before the last day of class, so almost all of the course content is covered on the three exams before the final. Nevertheless, the coefficients for African American, Asian American, and Hispanic were $-0.117 \pm 0.058,-0.114 \pm 0.017$, and $-0.084 \pm 0.025$, respectively, in this model. These coefficients are represented graphically in Fig. 4.

\section{DISCUSSION}

Our findings suggest that statistical results examining equity in university physics courses may be highly dependent on how students are grouped by race and ethnicity in the models. Grouping students as URMs or not and defining non-URMs as White and Asian may mask difficulties that Asian American, African American, and Hispanic students all face in their physics courses. It appears that model 3, which included URM, ACT math, and physics placement test as predictors, has a small, nonsignificant coefficient for URM because of how Asian American, African American, Hispanic, and White populations were grouped together and the relative performance of the groups. Hispanic students earned higher test scores than African American students and had a lower statistical penalty for their race in the models than did African Americans, as indicated by the coefficients of $-0.134 \pm 0.036$ for Hispanic students and $-0.300 \pm 0.080$ for African American students in model 6. Meanwhile, Asian American students underperformed on the final exam with respect to their precollege test scores relative to their non-Hispanic White American peers, who earned lower ACT math and physics placement test scores than Asian American students but nevertheless earned higher exam scores in the introductory mechanics course. 
Overall, the relatively strong performance of Hispanic students compared to African American students and the weak performance of Asian American students compared to White students results in a washing out of the effects of belonging to all four groups in model 3. Grouping students in this binary way could lead us to the conclusion that K-12 preparation accounts for the performance differences we see in students from different racial and ethnic groups. However, the more differentiated models of Tables V and VII suggest that students of different racial and ethnic groups continue to be subject to inequities in their educational experiences at the college level. Studies on the experiences of students in these groups offer some insight into what may be going on during what is for most of these students the first year of college.

Challenges that African American students face in college that are entirely unrelated to their academic ability are well documented, and efforts to increase their participation in higher education and reduce or remove these inequitable barriers are rightly a priority in the education community. The TEAM-UP report [21] produced by the American Institute of Physics in 2020 documents some of the challenges African American students face and provides recommendations to better support this group of students. In particular, the report discusses the struggle to obtain a sense of belonging and the feelings of isolation often reported by Black physics students as well as experiences of imposter syndrome and stereotype threat. Banks corroborated these findings in her phenomenological qualitative study documented in Black Women Undergraduates, Cultural Capital, and College Success [22]. Interviews with African American female college students revealed obstacles of racism, sexism, and classism facing these students as well as strategies that African American women have developed to navigate these issues. Fries-Britt, Younger, and Hall reported the experiences of students of color with professors who either directly discouraged them from pursuing a science, technology, engineering, and mathematics degree or indirectly made them feel less valued in the classroom than other students [23]. Students reported constantly feeling like they needed to prove themselves, a sentiment emphasized in Banks' study as well. These types of stressors facing African American students could certainly impact their performance in their physics coursework.

Although they are not generally the focus of most academic equity literature, there may be cause for concern for Asian American students as well. Since the late 1970s, Asian American students have been "deminoritized" based on their K-12 academic success and overrepresentation in higher education $[24,25]$. However, the model minority stereotype has allowed difficulties faced by Asian American college students to go largely unnoticed because of the assumption that these students are doing well [26]. Nevertheless, several studies have quantified Asian Americans' academic struggles in college, finding that, on average, Asian Americans earned lower GPAs in college than their European American counterparts $[25,27,28]$. Qualitative studies add more depth to the research community's understanding of the Asian American college experience. A study by Wang found that Asian American college students experience racism and discrimination and perceive a lack of support from their academic institution. The students in Wang's study reported feeling an intense pressure to live up to the high academic expectations that society has placed on them as Asian Americans and a reluctance to seek out mental health support [29]. Similarly, in a focus group study of 1.5 and 2nd generation Asian American young adults, Sunmin Lee et al. found that participants reported experiencing stress from feeling a need to live up to the model minority stereotype and their parents' high academic expectations, the challenge of living in two cultures, and discrimination and isolation based on their race and ethnicity [30]. As with Wang's cohort of study participants, Lee's participants generally did not feel comfortable seeking mental health support because of stigma surrounding mental health issues and concerns around finding a mental health professional who understood their culture. If a group of students is under a significant amount of stress but generally does not utilize the mental health resources available to them, this could lead to some degree of academic difficulty.

Our statistical results do not provide any insight into the qualitative experiences of the students in our study. However, they do suggest that African American and Asian American students are struggling disproportionately, and a qualitative examination of the experiences of these first-year engineering students taking physics 1 is the next step in identifying how we can achieve greater equity in our courses.

\section{CONCLUSION}

The strong dependence of the statistical outcomes on student grouping revealed by this study serves as a reminder that it is important to examine classification structures and identify trends within subgroups that may be rendered invisible when considered at a broader scale. Although we recognize the trade-offs between small group sizes and statistical power, we recommend running descriptive statistics and possibly constructing statistical models with disaggregated race and ethnicity data before forming larger groups for statistical analysis. To acquire more statistical power with which to detect statistical effects, it can be useful to work with multiyear or multi-institutional data. When working with these data, it is important to examine the data for trends by year or institution before aggregating it and to incorporate year and institution into the statistical analysis if warranted.

The study raises many questions around why students in minority groups are not doing as well on their physics final exam as non-Hispanic White American students with the same ACT math and placement test scores. There may be something about the physics course, the engineering program, or student culture that prevents Asian American and African American students, and to a lesser extent, Hispanic students, from realizing their full potential. Because data from only one institution were used, replication of the study at other institutions may be warranted to determine whether the disparities found in our analysis are 
more widespread. It would also be interesting to conduct the same analysis on student performance in other first-year engineering courses, such as the introductory calculus sequence, or in courses taken by nonengineering students to see if the trends detected by our analysis extend to other disciplines. In addition to replicating this analysis with other datasets, this study certainly motivates us to conduct further qualitative inquiries into the experiences of students of color to understand the challenges they face and identify ways in which we can better support them.

\section{ACKNOWLEDGMENTS}

This research was partially supported by NSF Grant No. DRL 20-10188. The authors would also like to acknowledge the students and instructors of the physics 1 course at the University of Illinois at Urbana-Champaign (UIUC), Rebecca Wiltfong for anonymizing and providing access to the data, the Physics Education Research Group at UIUC, particularly Eric Kuo, Katie Ansell, Gabriel Ehrlich, and Robeson Graham-Bailey, as well as Eric Burkholder, Shima Salehi, Carl Wieman, and Nikki Colton for thoughtful commentary.

\section{APPENDIX A: FALL DATA ANALYSIS}

The analysis conducted using the spring data is repeated using the fall data in Tables VIII-XIII.

TABLE VIII. Means and standard deviations of enrollment numbers and test scores, fall data.

\begin{tabular}{lrr}
\hline \hline Characteristic & Mean & SD \\
\hline Students per term & 727 & 92 \\
Math ACT score (out of 36) & 33 & 3 \\
Placement test score & $83 \%$ & $18 \%$ \\
First exam score & $81 \%$ & $16 \%$ \\
Second exam score & $80 \%$ & $16 \%$ \\
Third exam score & $78 \%$ & $17 \%$ \\
Final exam score & $78 \%$ & $17 \%$ \\
\hline \hline
\end{tabular}

TABLE IX. Student demographics, fall data.

\begin{tabular}{lcc}
\hline \hline Group & Number & Percentage \\
\hline AIAN $^{\mathrm{a}}$ & 5 & $<1$ \\
Asian American & 1968 & 30 \\
African American & 120 & 2 \\
Hispanic & 386 & 6 \\
International & 1395 & 21 \\
Multirace & 227 & 3 \\
NHPI & 6 & $<1$ \\
Non-Hispanic White American & 2438 & 37 \\
Total & 6545 & 100 \\
\hline \hline
\end{tabular}

\footnotetext{
${ }^{\mathrm{a}}$ American Indian/Alaskan Native.
}

${ }^{\mathrm{b}}$ Native Hawaiian/Pacific Islander.

TABLE X. Mean test scores by group, fall data. ACT Math scores are reported as raw scores, whereas the remaining exam scores are reported as percentages. Standard deviations are included in parentheses.

\begin{tabular}{lcccccc}
\hline \hline Group & ACT math & Placement test $(\%)$ & Exam 1 $(\%)$ & Exam 2 $(\%)$ & Exam 3 $(\%)$ & Final exam $(\%)$ \\
\hline African American & $29(4)$ & $64(21)$ & $66(18)$ & $63(17)$ & $63(19)$ & $62(18)$ \\
Asian American & $34(2)$ & $85(15)$ & $80(15)$ & $79(15)$ & $77(16)$ & $77(16)$ \\
Hispanic & $30(4)$ & $67(24)$ & $72(19)$ & $69(19)$ & $69(20)$ & $68(21)$ \\
International & $35(1)$ & $92(12)$ & $87(14)$ & $85(14)$ & $84(15)$ & $85(16)$ \\
Multirace & $33(3)$ & $82(17)$ & $80(15)$ & $78(16)$ & $77(17)$ & $78(17)$ \\
Non-Hispanic White American & $34(3)$ & $81(18)$ & $82(15)$ & $80(15)$ & $79(16)$ & $78(17)$ \\
URM & $31(4)$ & $70(23)$ & $73(19)$ & $69(18)$ & $69(19)$ & $68(20)$ \\
Non-URM & $34(2)$ & $85(16)$ & $82(15)$ & $81(15)$ & $80(16)$ & $79(17)$ \\
\hline \hline
\end{tabular}


TABLE XI. Binary models predicting physics 1 final exam scores, fall data.

\begin{tabular}{|c|c|c|c|c|c|c|c|c|c|}
\hline \multirow[b]{2}{*}{ Predictor } & \multicolumn{3}{|c|}{ Model 10} & \multicolumn{3}{|c|}{ Model 11} & \multicolumn{3}{|c|}{ Model 12} \\
\hline & $\beta$ & $\mathrm{SE}$ & $p$ & $\beta$ & SE & $p$ & $\beta$ & SE & $p$ \\
\hline URM & -0.638 & 0.046 & $<0.001$ & -0.157 & 0.042 & $<0.001$ & -0.089 & 0.041 & 0.031 \\
\hline ACT math & & & & 0.424 & 0.013 & $<0.001$ & 0.275 & 0.015 & $<0.001$ \\
\hline Placement test & & & & & & & 0.284 & 0.014 & $<0.001$ \\
\hline$\chi^{2}$ & & 188.4 & & & 1248.0 & & & 1668.2 & \\
\hline$d f$ & & 1 & & & 2 & & & 3 & \\
\hline$p$ & & $<0.001$ & & & $<0.001$ & & & $<0.001$ & \\
\hline
\end{tabular}

TABLE XII. Differentiated models predicting physics 1 final exam scores, fall data. ${ }^{\text {a }}$

\begin{tabular}{|c|c|c|c|c|c|c|c|c|c|}
\hline \multirow[b]{2}{*}{ Predictor } & \multicolumn{3}{|c|}{ Model 13} & \multicolumn{3}{|c|}{ Model 14} & \multicolumn{3}{|c|}{ Model 15} \\
\hline & $\beta$ & SE & $p$ & $\beta$ & SE & $p$ & $\beta$ & SE & $p$ \\
\hline African American & -0.944 & 0.098 & $<0.001$ & -0.337 & 0.095 & $<0.001$ & -0.262 & 0.090 & 0.004 \\
\hline Asian American & -0.063 & 0.029 & 0.029 & -0.232 & 0.027 & $<0.001$ & -0.243 & 0.026 & $<0.001$ \\
\hline Hispanic & -0.610 & 0.065 & $<0.001$ & -0.210 & 0.057 & $<0.001$ & -0.125 & 0.056 & 0.024 \\
\hline International & 0.378 & 0.031 & $<0.001$ & 0.097 & 0.030 & 0.001 & 0.010 & 0.029 & 0.725 \\
\hline Multirace & -0.036 & 0.067 & 0.587 & -0.053 & 0.058 & 0.359 & -0.073 & 0.056 & 0.196 \\
\hline ACT math & & & & 0.421 & 0.014 & $<0.001$ & 0.286 & 0.015 & $<0.001$ \\
\hline Placement test & & & & & & & 0.278 & 0.015 & $<0.001$ \\
\hline$\chi^{2}$ & & 444.7 & & & 1385.1 & & & 1789.8 & \\
\hline$d f$ & & 7 & & & 8 & & & 9 & \\
\hline$p$ & & $<0.001$ & & & $<0.001$ & & & $<0.001$ & \\
\hline
\end{tabular}

${ }^{\text {a } A I A N ~ a n d ~ N H P I ~ s t u d e n t s ~ w e r e ~ i n c l u d e d ~ i n ~ t h e ~ m o d e l, ~ b u t ~ t h e ~ c o e f f i c i e n t s ~ f o r ~ t h e s e ~ g r o u p s ~ a r e ~ n o t ~ r e p o r t e d ~ h e r e ~ t o ~ p r o t e c t ~ t h e ~ p r i v a c y ~}$ of the students, since these groups are very small.

TABLE XIII. Models with course exam scores predicting physics 1 final exam scores, fall data.

\begin{tabular}{|c|c|c|c|c|c|c|c|c|c|}
\hline \multirow[b]{2}{*}{ Predictor } & \multicolumn{3}{|c|}{ Model 16} & \multicolumn{3}{|c|}{ Model 17} & \multicolumn{3}{|c|}{ Model 18} \\
\hline & $\beta$ & SE & $p$ & $\beta$ & SE & $p$ & $\beta$ & SE & $p$ \\
\hline African American & -0.114 & 0.072 & 0.115 & -0.012 & 0.066 & 0.862 & 0.025 & 0.059 & 0.672 \\
\hline Asian American & -0.109 & 0.023 & $<0.001$ & -0.047 & 0.020 & 0.021 & -0.023 & 0.018 & 0.195 \\
\hline Hispanic & -0.073 & 0.049 & 0.138 & -0.026 & 0.044 & 0.559 & -0.004 & 0.037 & 0.911 \\
\hline International & 0.037 & 0.024 & 0.123 & 0.033 & 0.021 & 0.115 & 0.032 & 0.019 & 0.088 \\
\hline Multirace & -0.016 & 0.048 & 0.736 & 0.011 & 0.043 & 0.793 & 0.041 & 0.036 & 0.256 \\
\hline ACT math & 0.133 & 0.014 & $<0.001$ & 0.056 & 0.012 & $<0.001$ & 0.039 & 0.010 & $<0.001$ \\
\hline Placement test & 0.137 & 0.013 & $<0.001$ & 0.063 & 0.012 & $<0.001$ & 0.044 & 0.010 & $<0.001$ \\
\hline Exam 1 & 0.518 & 0.015 & $<0.001$ & 0.290 & 0.013 & $<0.001$ & 0.181 & 0.012 & $<0.001$ \\
\hline Exam 2 & & & & 0.479 & 0.015 & $<0.001$ & 0.273 & 0.014 & $<0.001$ \\
\hline Exam 3 & & & & & & & 0.436 & 0.018 & $<0.001$ \\
\hline$\chi^{2}$ & & 4087.7 & & & 6395.2 & & & 9847.5 & \\
\hline$d f$ & & 10 & & & 11 & & & 12 & \\
\hline$p$ & & $<0.001$ & & & $<0.001$ & & & $<0.001$ & \\
\hline
\end{tabular}

\section{APPENDIX B: CORRELATION COEFFICIENTS}

The correlations coefficients among continuous variables are shown in Table XIV. 
TABLE XIV. Correlation coefficients for continuous variables, spring data.

\begin{tabular}{|c|c|c|c|c|c|}
\hline Variable & $\begin{array}{l}\text { ACT } \\
\text { math }\end{array}$ & $\begin{array}{l}\text { Physics } \\
\text { placement } \\
\text { test }\end{array}$ & Exam 1 & Exam 2 & Exam 3 \\
\hline $\begin{array}{l}\text { Physics } \\
\text { placement } \\
\text { test }\end{array}$ & 0.442 & & & & \\
\hline Exam 1 & 0.366 & 0.303 & & & \\
\hline Exam 2 & 0.367 & 0.362 & 0.613 & & \\
\hline Exam 3 & 0.305 & 0.312 & 0.585 & 0.657 & \\
\hline Final exam & 0.332 & 0.338 & 0.638 & 0.692 & 0.735 \\
\hline
\end{tabular}

\section{APPENDIX C: PHYSICS PLACEMENT TEST}

The purpose of this diagnostic instrument is to identify students who would benefit from extra instruction in how to approach physics problems. This extra instruction takes the form of the 1-2 h class PHYS 100. This diagnostic also helps to assess some previous physics and mathematics knowledge.

Select the answer you think best to each of these multiple-choice questions. You will probably need a pencil and scratch paper to work out some of the problems. You may also use a calculator. If you have no idea how to solve the problem and would just be making a random guess, select "I can't eliminate any choices." This gives us a more accurate assessment of your physics and math preparation than having you randomly guess answers. If you can eliminate at least one or two choices, select the answer that you think is best.

INTRODUCTION These first three questions tell us a little about your background.

I. How many years of high school physics did you take?

a. 0 years b. 1 year c. 2 or more years

II. If you took any physics in high school, how would you rate the quality of the class?

a. Good b. Fair c. Poor d. I didn't take any physics in high school

III. Do you think you will have trouble passing PHYS 211?

a. Yes b. No, but I will probably take PHYS 100 if it's recommended c. No, and I probably won't probably take PHYS 100 if it's recommended

The remaining questions test your math and physics preparedness.

1. A ball is thrown straight up in the air with a velocity of $40 \mathrm{~m} / \mathrm{s}$. Neglecting air resistance, how long will the ball be in the air?

a. Time $=3.57 \mathrm{~s}$ b. Time $=8.16 \mathrm{~s} \mathrm{c}$. Time $=12.46 \mathrm{~s}$ d. Time $=20 \mathrm{~s}$ e. Time $=40 \mathrm{~s}$ f. I can't eliminate any choices

2. Car A leaves town heading east with a constant speed of $20 \mathrm{miles} / \mathrm{hr}$. An hour later car B leaves town heading east as well, with a constant speed of 25 miles/hr. How long after car B leaves will it intercept car A?

a. Half an hour later b. Two hours later c. Three hours later d. Four hours later e. Five hours later f. I can't eliminate any choices

3. A child runs at speed $v_{c}$, while an adult runs at speed $v_{a}$. If the adult gives the child a head start of distance d, how long will it take for the adult to catch the child? Express your answer in terms of $v_{a}, v_{c}$, and d.

a. $d /\left(v_{a}+v_{c}\right)$ b. $d /\left(v_{a}-v_{c}\right)$ c. $\left(v_{c}+d\right) / v_{a}$ d. $d / v_{a}$ e. I can't eliminate any choices

4. A ball is orbiting counterclockwise at 100 revolutions per minute $(\mathrm{rpm})$ around a circle of radius $10 \mathrm{~cm}$. The center of the circle is at the $\mathrm{x}-\mathrm{y}$ origin $(0,0)$. At $t=0$, the ball is at $(10 \mathrm{~cm}, 0)$. When does the ball first reach the y axis?

a. $t=0.15 \mathrm{sec}$ b. $t=0.20 \mathrm{sec}$ c. $t=0.25 \mathrm{sec}$ d. $t=0.30 \mathrm{sec}$ e. I can't eliminate any choices

5. This graph [Figure 5] shows the velocity of an object versus time. At which time does the object change its direction of motion?

a. $1.5 \mathrm{~s} \mathrm{~b} .3 \mathrm{~s} \mathrm{c} .4 \mathrm{~s} \mathrm{~d} .5 \mathrm{~s}$ e. None of the above

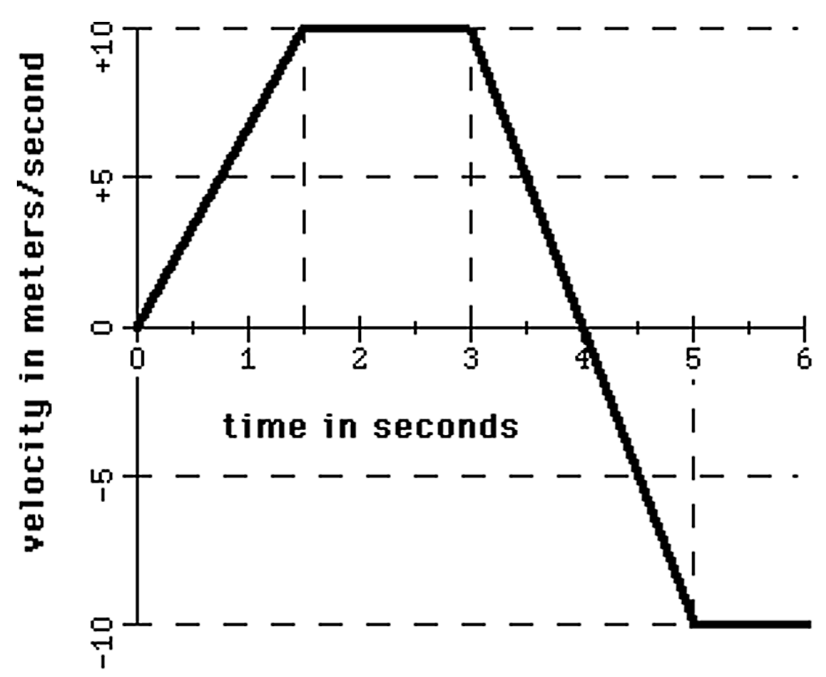

FIG. 5. Graph corresponding to question 5. (a)

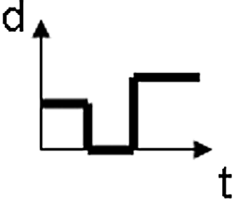

(c)

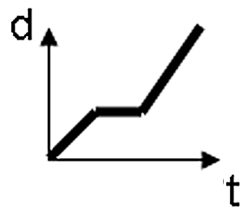

(b)

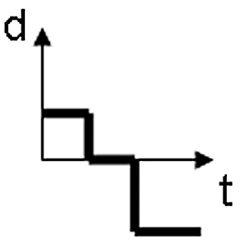

(d)

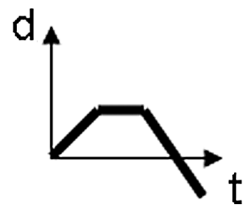

FIG. 6. Answer choices for question 6 . 


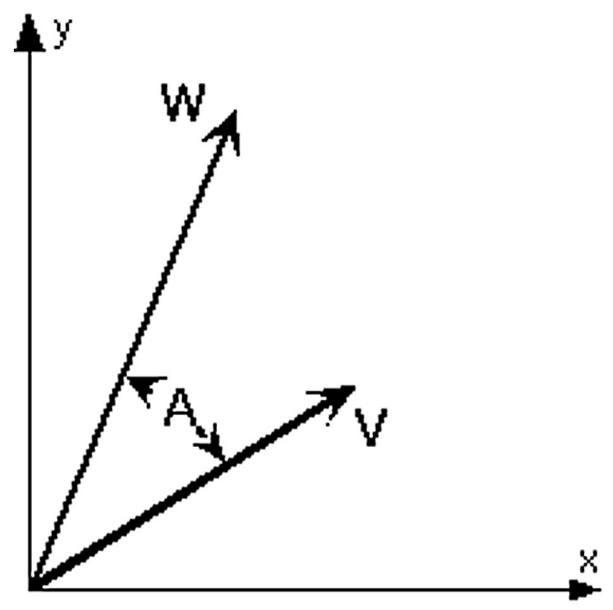

FIG. 7. Graph corresponding to questions 7 and 8 .

6. A car drives east for two hours at 40 miles per hour. After stopping for two hours, it then drives east for another three hours at 60 miles per hour. Which of the following graphs [Figure 6] correctly represents the distance versus time for this motion?

e. I can't eliminate any choices

The next two questions deal with the following situation [Figure 7]: Here we have two vectors $\mathrm{V}$ and $\mathrm{W}$. The angle between these vectors is A.

7. What is the component of $\mathrm{V}$ parallel to $\mathrm{W}$ in terms of $\mathrm{A}$ and the magnitudes of $\mathrm{V}$ and $\mathrm{W}$ ?

a. $\mathrm{V}$ b. $\mathrm{W}$ c. $\mathrm{V} \sin (\mathrm{A})$ d. $\mathrm{V} \cos (\mathrm{A})$ e. $\mathrm{W} \sin (\mathrm{A})$ f. $\mathrm{W} \cos$ (A) g. I can't eliminate any choices

8. What is the component of $\mathrm{V}$ perpendicular to $\mathrm{W}$ in terms of $\mathrm{A}$ and the magnitudes of $\mathrm{V}$ and $\mathrm{W}$ ?

a. V b. W c. V $\sin (\mathrm{A})$ d. $\mathrm{V} \cos (\mathrm{A})$ e. $\mathrm{W} \sin (\mathrm{A}) \mathrm{f}$. $\mathrm{W} \cos$ (A) g. I can't eliminate any choices

The next two questions deal with the following situation: The two vectors $A$ and $B$ are defined as: $A=(3 \mathrm{~m}, 4 \mathrm{~m})$ and $B=(5 \mathrm{~m},-3 \mathrm{~m})$, where the first number is the $\mathrm{x}$-component of the vector, and the second number is the y-component of the vector.

9. What is the magnitude of vector A? a. 7 m b. 4 m c. $(8 \mathrm{~m}, 1 \mathrm{~m})$ d. 5 m e. $(3 \mathrm{~m}, 4 \mathrm{~m})$ f. I can't eliminate any choices

10. What is $\mathrm{A}+\mathrm{B}$ ?

a. $(8 \mathrm{~m}, 1 \mathrm{~m})$ b. $7 \mathrm{~m}$ c. $(3 \mathrm{~m}, 1 \mathrm{~m})$ d. $10.83 \mathrm{~m}$ e. $5.83 \mathrm{~m}$ f. $(7 \mathrm{~m}, 2 \mathrm{~m}) \mathrm{g}$. I can't eliminate any choices

11. In the year 2003 the Acme Company has twice as many employees as managers. During the next 5 years, they hire twelve employees and fire two managers. Which of the following equations is correct for the current number of managers $\left(N_{M 2008}\right)$ and the current number of employees $\left(N_{E 2008}\right)$ ?

a. $\quad N_{M 2008}+2=2\left(N_{E 2008}-12\right) \quad$ b. $\quad N_{M 2008}-2=$ $2\left(N_{E 2008}+12\right) \quad$ c. $\quad 2\left(N_{M 2008}+2\right)=N_{E 2008}-12$ d. $2\left(N_{M 2008}-2\right)=N_{E 2008}+12$ e. I can't eliminate any choices

The next two questions both use the following information: The force on an object in uniform circular motion is given by $F=m v^{2} / r$.

12. Consider two equal-mass objects moving around the same circle, one with speed $v_{1}$ and one with speed $v_{2}$, where $v_{1}=2 v_{2}$. What is the ratio of the forces on these two objects?
a. $F_{1} / F_{2}=1 \quad$ b. $\quad F_{1} / F_{2}=2 \quad$ c. $\quad F_{1} / F_{2}=4$ d. $F_{1} / F_{2}=1 / 2$ e. $F_{1} / F_{2}=1 / 4$

13. Now the two objects move at the same speed around the same circle but have different masses $m_{1}$ and $m_{2}$, where $m_{1}=2 m_{2}$. What is the ratio of the forces on the two objects?
a. $\quad F_{1} / F_{2}=1$
b. $\quad F_{1} / F_{2}=2$
c. $\quad F_{1} / F_{2}=4$ d. $F_{1} / F_{2}=1 / 2$ e. $F_{1} / F_{2}=1 / 4$

\section{APPENDIX D: GENDER MODELS}

We ran the same analysis with gender as we did with URM status, coding female as 1 and male as 0 in the binary variable for gender (the registrar data included only binary gender information). 6502 (76\%) of the students were male and 2051 (24\%) were female. The test scores of each group are reported in Table $\mathrm{XV}$, and the results of a series of multiple linear regressions are shown in Tables XVI and XVII.

TABLE XV. Mean test scores by gender. ACT Math scores are reported as raw scores, whereas the remaining exam scores are reported as percentages. Standard deviations are included in parentheses.

\begin{tabular}{lcccccc}
\hline \hline Group & ACT math & Placement test $(\%)$ & Exam 1 (\%) & Exam 2 (\%) & Exam 3 (\%) & Final exam $(\%)$ \\
\hline Female & $32(3)$ & $71(21)$ & $76(17)$ & $73(16)$ & $74(16)$ & $71(17)$ \\
Male & $32(3)$ & $75(19)$ & $81(15)$ & $78(14)$ & $77(16)$ & $76(16)$ \\
\hline \hline
\end{tabular}


TABLE XVI. Binary gender models predicting physics 1 final exam scores. Female is coded as 1 and male is coded as 0 for the gender variable. Continuous variables are standardized.

\begin{tabular}{|c|c|c|c|c|c|c|c|c|c|c|c|c|}
\hline \multirow[b]{2}{*}{ Predictor } & \multicolumn{3}{|c|}{ Model 19} & \multicolumn{3}{|c|}{ Model 20} & \multicolumn{3}{|c|}{ Model 21} & \multicolumn{3}{|c|}{ Model 22} \\
\hline & $\beta$ & SE & $p$ & $\beta$ & SE & $p$ & $\beta$ & SE & $p$ & $\beta$ & SE & $p$ \\
\hline $\begin{array}{l}\text { Female } \\
\text { ACT math } \\
\text { Placement test } \\
\text { Female*ACT math }\end{array}$ & -0.269 & 0.025 & $<0.001$ & $\begin{array}{c}-0.221 \\
0.326\end{array}$ & $\begin{array}{l}0.024 \\
0.010\end{array}$ & $\begin{array}{l}<0.001 \\
<0.001\end{array}$ & $\begin{array}{c}-0.189 \\
0.225 \\
0.232\end{array}$ & $\begin{array}{l}0.023 \\
0.011 \\
0.011\end{array}$ & $\begin{array}{l}<0.001 \\
<0.001 \\
<0.001\end{array}$ & $\begin{array}{c}-0.182 \\
0.201 \\
0.232 \\
0.098\end{array}$ & $\begin{array}{l}0.023 \\
0.012 \\
0.011 \\
0.023\end{array}$ & $\begin{array}{l}<0.001 \\
<0.001 \\
<0.001 \\
<0.001\end{array}$ \\
\hline $\begin{array}{l}F \\
d f \\
\text { adj. } R^{2} \\
p\end{array}$ & & $\begin{array}{c}114.7 \\
1,8551 \\
0.013 \\
<0.001\end{array}$ & & & $\begin{array}{c}579.1 \\
2,8550 \\
0.119 \\
<0.001\end{array}$ & & & $\begin{array}{c}552.0 \\
3,8549 \\
0.162 \\
<0.001\end{array}$ & & & $\begin{array}{c}419.4 \\
4,8548 \\
0.164 \\
<0.001\end{array}$ & \\
\hline $\begin{array}{l}\chi^{2} \\
d f \\
p\end{array}$ & & $\begin{array}{c}109.5 \\
1 \\
<0.001\end{array}$ & & & $\begin{array}{c}1142.6 \\
2 \\
<0.001\end{array}$ & & & $\begin{array}{c}1744.8 \\
3 \\
<0.001\end{array}$ & & & $\begin{array}{c}1777.9 \\
4 \\
<0.001\end{array}$ & \\
\hline
\end{tabular}

TABLE XVII. Multiple linear regression models of physics 1 final exam scores on gender, ACT math scores, physics placement test scores, and course exam scores. Female is coded as 1 and male is coded as 0 for the gender variable. Continuous variables are standardized. Only the Wald test results are reported because the models violated the multiple linear regression assumption of homogeneity of variances. The error bars and $p$-values were adjusted to account for this violation.

\begin{tabular}{|c|c|c|c|c|c|c|c|c|c|}
\hline \multirow[b]{2}{*}{ Predictor } & \multicolumn{3}{|c|}{ Model 23} & \multicolumn{3}{|c|}{ Model 24} & \multicolumn{3}{|c|}{ Model 25} \\
\hline & $\beta$ & SE & $p$ & $\beta$ & SE & $p$ & $\beta$ & SE & $p$ \\
\hline Female & -0.039 & 0.019 & 0.040 & -0.003 & 0.017 & 0.845 & -0.012 & 0.015 & 0.440 \\
\hline ACT math & 0.062 & 0.010 & $<0.001$ & 0.014 & 0.009 & 0.144 & 0.010 & 0.008 & 0.203 \\
\hline Placement test & 0.136 & 0.009 & $<0.001$ & 0.065 & 0.009 & $<0.001$ & 0.041 & 0.008 & $<0.001$ \\
\hline Exam 1 & 0.571 & 0.011 & $<0.001$ & 0.330 & 0.012 & $<0.001$ & 0.212 & 0.011 & $<0.001$ \\
\hline Exam 2 & & & & 0.461 & 0.013 & $<0.001$ & 0.268 & 0.012 & $<0.001$ \\
\hline Exam 3 & & & & & & & 0.419 & 0.017 & $<0.001$ \\
\hline$\chi^{2}$ & & 5420.3 & & & 8231.1 & & & 11249.1 & \\
\hline$d f$ & & 4 & & & 5 & & & 6 & \\
\hline$p$ & & $<0.001$ & & & $<0.001$ & & & $<0.001$ & \\
\hline
\end{tabular}

[1] American Psychological Association, Ethnic and racial minorities and socioeconomic status, https:/www.apa.org/ pi/ses/resources/publications/factsheet-erm.pdf (2017).

[2] E. Brewe, V. Sawtelle, L. Kramer, and G. O’Brien, Toward equity through participation in Modeling Instruction in introductory university physics, Phys. Rev. ST Phys. Educ. Res. 6, 010106 (2010).

[3] D. Haak, J. HilleRisLambers, E. Pitre, and S. Freeman, Increased structure and active learning reduce the achievement gap in introductory biology, Science 332, 1213 (2011).

[4] C. Ballen, C. Wieman, S. Salehi, J. Searle, and K. Zamudio, Enhancing diversity in undergraduate science: Self-efficacy drives performance gains with active learning, CBE Life Sci. Educ. 16, ar56 (2017).
[5] S. Eddy and K. Hogan, Getting under the hood: How and for whom does increasing course structure work, CBE Life Sci. Educ. 13, 453 (2017).

[6] S. Getty, N. Gosnell, B. Whitten, and J. Taylor, Supporting inclusive teaching in introductory college physics, Phys. Teach. 58, 312 (2020).

[7] B. V. Dusen and J. Nissen, Associations between learning assistants, passing introductory physics, and equity: A quantitative critical race theory investigation, Phys. Rev. Phys. Educ. Res. 16, 010117 (2020).

[8] S. Salehi, E. Burkholder, G. Lepage, S. Pollack, and C. Wieman, Demographic gaps or preparation gaps?: The large impact of incoming preparation on performance of students in introductory physics, Phys. Rev. Phys. Educ. Res. 15, 020114 (2019). 
[9] D. Hestenes, M. Wells, and G. Swackhamer, Force Concept Inventory, Phys. Teach. 30, 141 (1992).

[10] R. Thornton and D. Sokoloff, Assessing student learning of Newton's laws: The Force and Motion Conceptual Evaluation, Am. J. Phys. 66, 338 (1998).

[11] ACT, 2018 act-sat concordance tables, https://www .act.org/content/dam/act/unsecured/documents/ACT-SATConcordance-Tables.pdf (2018).

[12] R Core Team, R: A Language and Environment for Statistical Computing, R Foundation for Statistical Computing, Vienna, Austria (2018).

[13] A. Zeileis and T. Hothorn, Diagnostic checking in regression relationships, R News 2, 7 (2002), https://cran. r-project.org/web/packages/lmtest/vignettes/lmtest-intro .pdf.

[14] A. Zeileis, Econometric computing with HC and HAC covariance matrix estimators, J. Stat. Softw. 11, 1 (2004).

[15] M. Lesnoff and R. Lancelot, aod: Analysis of Overdispersed Data (2012), R package version 1.3.1.

[16] D. Bates, M. Mächler, B. Bolker, and S. Walker, Fitting linear mixed-effects models using lme4, J. Stat. Softw. 67, 1 (2015).

[17] D. Lüdecke, sjstats: Statistical Functions for Regression Models (Version 0.18.0) (2020).

[18] E. Theobald, Students are rarely independent: When, why, and how to use random effects in discipline-based education research, CBE Life Sci. Educ. 17, 17:rm2 (2018).

[19] For completeness, we have reported results from an analogous statistical analysis using gender as a demographic variable in Appendix D.

[20] H. Wickham, ggplot2: Elegant Graphics for Data Analysis (Springer-Verlag, New York, 2016).

[21] AIP National Task Force to Elevate African American Representation in Undergraduate Physics \& Astronomy (TEAM-UP), The Time is Now: Systemic Changes to Increase African Americans with Bachelor's Degrees in
Physics and Astronomy (American Institute of Physics, New York, 2020).

[22] C. Banks, Black Women Undergraduates, Cultural Capital, and College Success (Peter Lang Publishing, Inc., New York, 2009).

[23] S. Fries-Britt, T. Younger, and W. Hall, Lessons from highachieving students of color in physics, New Dir. Instit. Res. 2010, 75 (2010).

[24] S. Lee, Over-represented and de-minoritized: The racialization of Asian Americans in higher education, InterActions: UCLA J. Educ. Inform. Studies 2, 5 (2006), https://escholarship.org/uc/item/4r7161b2.

[25] J. Dmitrieva, E. Greenberger, and C. Chen, Whither the "Whiz Kids" went: Asian American students' transition to college, in Model Minority Myth Revisited: An Interdisciplinary Approach to Demystifying Asian American Educational Experiences, edited by G. Li and L. Wang (Information Age Publishing, Charlotte, NC, 2008), pp. 233-251.

[26] J. Wing, Beyond black and white: The model minority myth and the invisibility of Asian American students, Urban Rev. 39, 455 (2007).

[27] Y.-W. Ying, P. Lee, J. Tsai, Y. Hung, M. Lin, and C. Wan, Asian American college students as model minorities: An examination of their overall competence, Cultural Div. Ethnic Minority Psychol. 7, 59 (2001).

[28] S. Kim, Asian American students' academic achievement: Reassessing early childhood and college, Ph.D. thesis, University of Iowa, 2018.

[29] J. Wang, Asian American College student well-being: Racial identity consciousness as model minorities at an Elite University, Ph.D. thesis, University of Southern California, 2019.

[30] S. Lee, H.-S. Juon, G. Martinez, C. Hsu, E. Robinson, J. Bawa, and G. Ma, Model minority at risk: Expressed needs of mental health by Asian American young adults, J. Community Health 34, 144 (2008). 